\title{
The colour of the facades in Siena's historical centre: I. Glazings (calcium oxalate films s.s.) and other finishes on the stone materials of the Cathedral's main facade
}

\author{
Francesca Droghini • Marco Giamello • \\ Giovanni Guasparri • Giuseppe Sabatini • Andrea Scala
}

Received: 12 December 2008 / Accepted: 9 June 2009 /Published online: 17 July 2009

(C) Springer-Verlag 2009

\begin{abstract}
This paper focuses on the long-debated topic of the so-called calcium oxalate films: their origin and meaning but also their age and original appearance. The restoration of the main facade of the Siena Cathedral provided a unique opportunity to this end, thanks to the possibility of an extensive and detailed sampling and (as rarely happens) a sufficiently accurate historical knowledge of the construction vicissitudes. This work, mainly based on a polarising microscopy study (coupled with X-ray diffraction and SEM-EDS analyses) of over a thousand thin and ultra-thin sections of 400 microsamples, demonstrates that the current relicts of films are the result of alteration and decay of ancient treatments. In most cases, these were linseed oil-based glazings (the use of this substance is confirmed by historical documents) and pigments. Their role was essentially aesthetic; their use dates the beginning of the fourteenth century and continued at least until the eighteenth century.
\end{abstract}

Keywords Siena Cathedral $\cdot$ Stone materials $\cdot$ Calcium oxalate films · Finishes

\footnotetext{
F. Droghini $(\bowtie) \cdot$ M. Giamello $\cdot$ G. Guasparri $\cdot$ G. Sabatini $\cdot$

A. Scala

Dipartimento di Scienze Ambientali,

U.R. Conservazione del Patrimonio Culturale Lapideo,

Università degli Studi di Siena,

Via Laterina 8,

53100 Siena, Italy

e-mail: droghini@unisi.it
}

\section{Introduction}

Despite the extensive literature on the so-called Ca-oxalate films on monumental surfaces, there is still no general consensus on what they really represent. Indeed, neither the first (Alessandrini 1989) nor the second (Realini and Toniolo 1996) international congress on this specific topic was successful in arriving at an unequivocal conclusion about the origin (natural or anthropic) of these films, although the second option (also shared by us) appeared to prevail among the many participating researchers. Papers published in the following years generally favour this interpretation (Polikreti and Maniatis 2003; Rampazzi et al. 2004; Maravelaki-Kalaitzaki 2005; Álvarez De Buergo Ballester 2007; Vazquez-Calvo et al. 2007), but some other still present different explanations (Garcia-Valles et al. 1998; Vendrell-Saz et al. 1996; Martin-Gil et al. 1999).

Probably because of this persisting uncertainty, few efforts have been devoted to other aspects bearing on the real meaning of these films, such as their possible age, the distribution (random or not) of the different typologies on a monument's surfaces or (assuming an anthropic origin) their appearance when applied and then whether they had aesthetic purposes or were simply meant to protect the stone surfaces. Answers to these questions are crucial to make any convincing conclusions about origins. Important contributions can derive primarily from detailed studies of extensive and architectonically varied surfaces, such as an entire monumental facade for which the edification vicissitudes be possibly well documented. We have successfully applied this approach to monumental Sienese facades mainly made of bricks, a 
commonly used man-made material (Giamello et al. 2005; Droghini et al. 2009). The results have demonstrated that the Ca-oxalate films are the remains of ancient finishes applied largely for aesthetic reasons and that these treatments mainly date to the time when the facade was built.

In this paper, we apply the same method to explore the meaning of Ca-oxalate films on natural stone materials, in particular marble, the stone on which the presence of $\mathrm{Ca}$ oxalate was first reported and which was subsequently at the centre of the aforesaid scientific debate. The recent (2006) restoration of Siena Cathedral's main facade provided a rare opportunity for this research and in particular to assess the conclusions reached on this topic in preceding works (Fommei et al. 1993; Giamello et al. 2005; Nardelli 2005). This monumental facade, in fact, offered not only all the necessary architectonic and lithological characteristics but also a notably detailed historical documentation of the construction events; moreover, a practically unlimited possibility of sampling (crucial for this kind of approach) was provided by the Opera della Metropolitana (OPA) management.

The facade is composed mainly of the three most typical local stones used in historical Sienese buildings (see the material mapping of Fig. 1): marble from the Montagnola Senese, red ammonitic limestone from Gerfalco and serpentinite from Vallerano quarries. The combined use of these materials is a clear indication of the designer's intention to give polychromy a fundamental role in the aesthetic appearance of the building.

The results of this study are quite in agreement with the above said intention since it will be concluded that the Caoxalate films are the remains of surface treatments whose characteristics allowed them to render homogeneous, highlight and maintain the typical colours of the stones and to create a better chromatic harmonisation of the entire facade.

In this paper, we will deal specifically with the aforesaid topic, ignoring the presence of other treatments identified during analyses of the samples, particularly the gilding and specific colouring of some ornamental elements already described in Droghini et al. (2007).

The overall study of the Cathedral is currently being expanded, with new samplings carried out in conjunction with the current restoration of the two side walls (south-east and north-west) and the external walls of the nave.

\section{Historical outline and sampling}

Modifications made to the facade for various reasons (structural problems, changes in aesthetic taste, degradation) must be considered for a correct interpretation of the macroscopic observations and analytical results. The valuable historical archive of the OPA provides ample information about such interventions, even though it is not

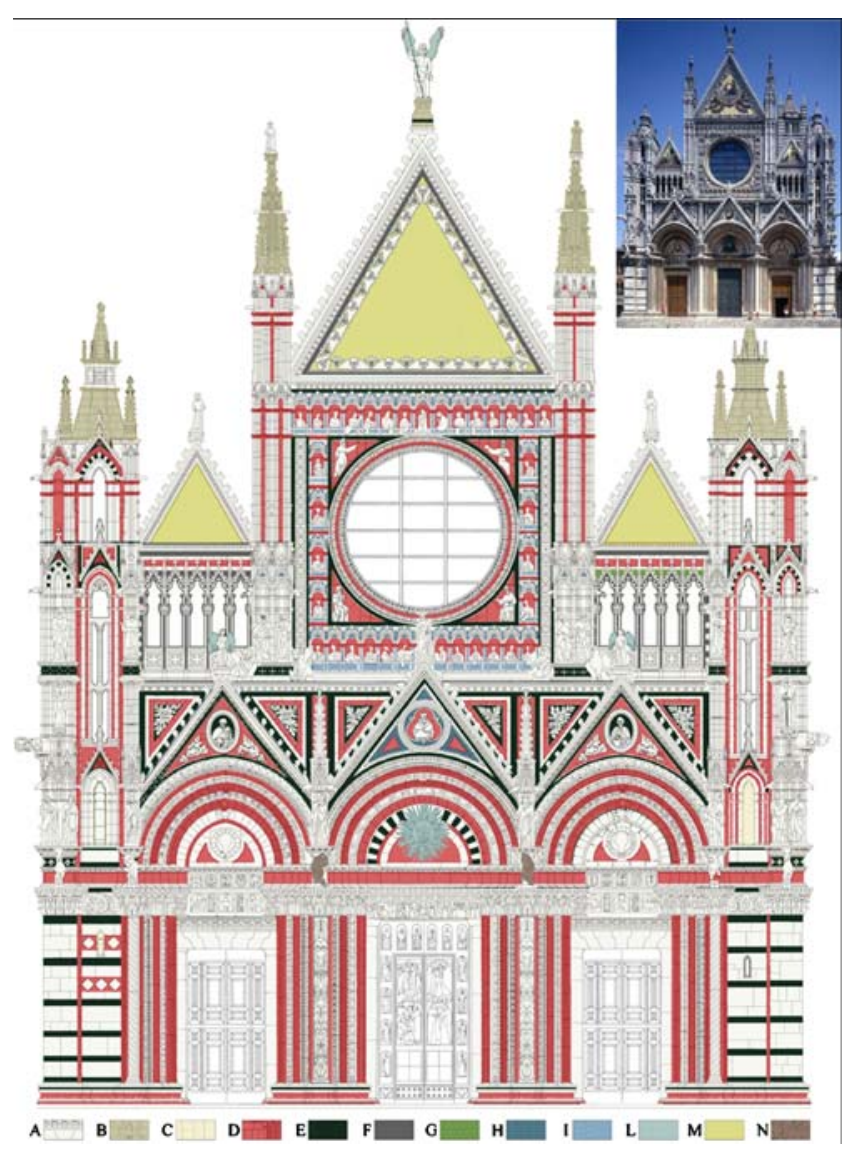

Fig. 1 Material mapping of the main facade of the Siena Cathedral from Droghini et al. (2007). $A$ Marble, $B$ travertine, $C$ alabaster, $D$ red ammonitic limestone, $E$ serpentinite, $F$ black limestone, $G$ 'verde Alpi' limestone, $H$ intarsia of stone elements, $I$ intarsia of vitreous elements, $L$ metallic elements, $M$ mosaics, $N$ fibreglass elements

always sufficiently detailed. Interventions probably began shortly after the original construction between 1284 and 1317 (Haas and Winterfeld 2006; Quast 2007) and have continued practically to the present day with replacement of the columns of Giovanni Pisano by copies (Table 1); complete information can be found in the literature (Carli 1979; Forlani Conti 1993; Haas and Winterfeld 2006). To all this must be added the innumerable substitutions (sometimes of only single stone elements) forming part of the ordinary maintenance of the facade and often evident upon careful observation of the surfaces.

In view of all these macro- and microinterventions, it must be concluded that only a small proportion of the surfaces is original. The mapping (Fig. 2) performed by Haas and von Winterfeld (1999) to distinguish the original and substituted parts allows a visual evaluation of the situation.

The sampling was heavily influenced by the very aggressive cleaning performed in previous restorations and the abnormally strong effect of rainfall on the surfaces. This phenomenon is extremely intense in the upper half of the facade, i.e. above the cornice delimiting the zone of the portals, 
Table 1 Modification in time of the facade

$1636-1659$

$1701-1704$

$1730-1732$

Late 1700 s-early 1800 s

$1866-1878$

1900 s
Important works promoted by Pope Alexander VII (born Fabio Chigi) involving much of the Cathedral, especially due to transfer of the Archiepiscopal Palace from its previous position, flanking the right side (south-east) of the Cathedral, to the current one next to the north-west side. This was followed by the stone facing of the south-east side (Butzek 1996). The facade was changed to adapt it to Baroque taste, e.g. inclusion of busts of three Sienese saints in the three cuspidate areas above the portals and covering of the surrounding bare areas with roses and foliage (Forlani Conti 1992)

Numerous substitutions in the splays of the three portals; the lunettes of the lateral portals with the coats of arms of the OPA were renewed and panels with bas-relief figures were inserted ex novo immediately below the lunettes (Butzek 2006)

Stone facing of the north-west side wall after demolition of the flanking priest's residence

After the disastrous earthquake of 1798, the seriously damaged facade underwent extensive restoration, including dismantling and reconstruction of one or perhaps both olimascoli (the two high pinnacles by the sides of the central tympanum) and heavy interventions to the side towers (Peduzzo 1993)

As part of an extensive restoration of the whole facade by Partini, substitutions were carried out especially in the upper half of the facade, e.g. reconstruction of the entire sector surrounding the rose window (except for most of its cornice), including the aedicules with busts of the ancestors of Christ, and total reconstruction of the mosaics in the three topmost triangles. In the lower half of the facade, the restoration mainly involved the area of the central portal: the Sienese saint in the central tympanum was surrounded by a Gothic cornice while the Baroque foliage was removed (Forlani Conti 1992; Loseries 2006)

There were also numerous interventions in the twentieth century, e.g. the removal-substitution of all the remaining valuable original statues (Peduzzo 1993) and, at last, the substitution of the columns of Giovanni Pisano

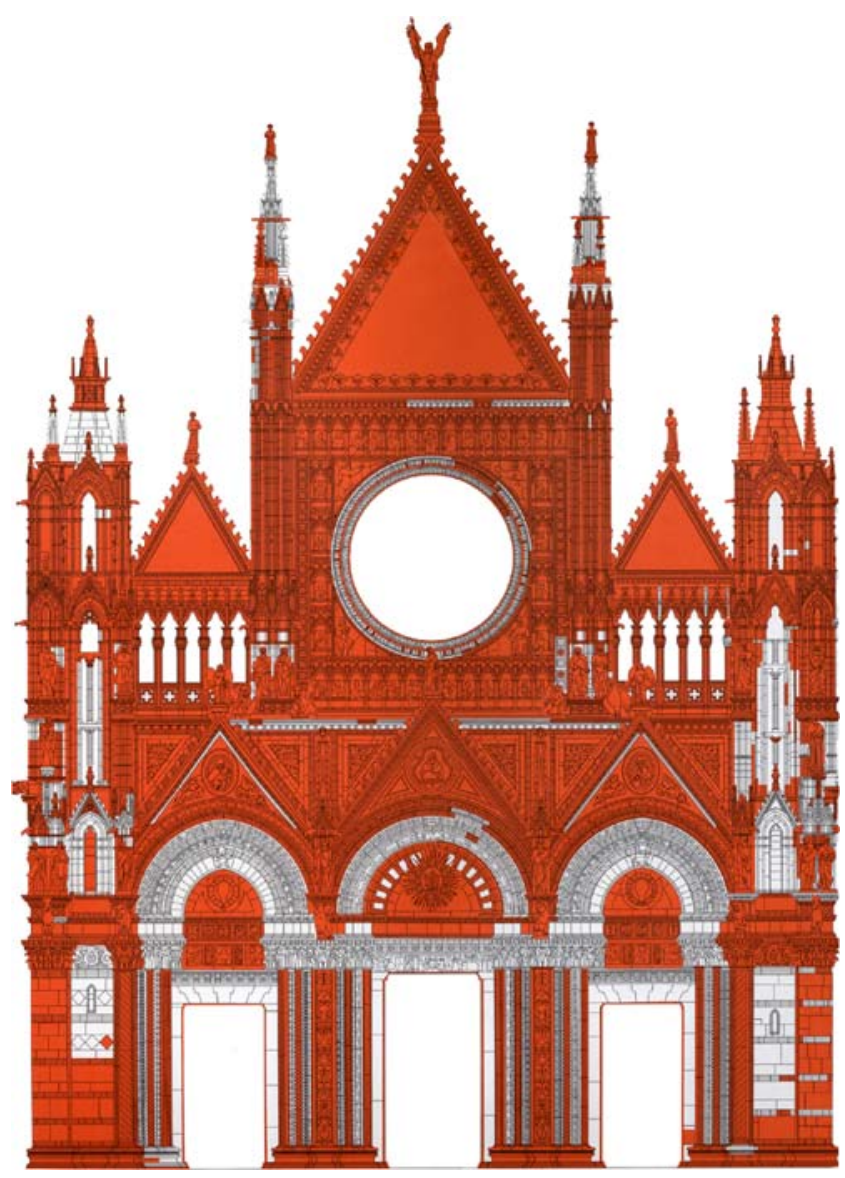

Fig. 2 Mapping carried out by Haas and von Winterfeld. White, original parts of the facade; red, substituted parts often resulting in strong generalised erosion of the surfaces, particularly of the fully exposed elements. Moreover, we could not take samples in some of the higher sectors (pinnacles of the side towers and 'olimascoli', middle-upper parts of the triangular mosaic areas), making only close-range observations used for the purpose of mapping the stone materials (Droghini et al. 2007). Lastly, we excluded a priori the surfaces with mosaics and all the statues, which in any case are mostly recent replacements of the originals.

It must also be considered that the resistance to decay of marble, red ammonitic limestone and serpentinite differs significantly (decreasing in this order). Moreover, unlike marble, the peculiar alteration mechanisms of the other two materials easily produce detachments, with loss of the superficial layer; this leads to a much lower probability of finding entire surfaces and thus samples useful for our purposes.

Despite these limitations, the sampling is to be considered exhaustive and suitable for the purpose of this research since it was possible to take samples of $\mathrm{Ca}$-oxalate films on all the various architectural surfaces (smooth wall, cornices, pilasters, capitals, arches, lunettes, tympanums, etc.) both from the original and the substituted parts of the facade. Sampling was usually performed after the cleaning of surface deposits (soilings, black crusts). This facilitated the macroscopic identification and sampling of the film residues. About 400 microsamples were collected.

\section{Methodology}

Firstly, all the microsamples were carefully examined under the stereomicroscope which provides a preliminary inspection 
of the existing microstratigraphic situation, essential both for the most suitable positioning of the sample slices to be used for thin sections and as a reference point for any final reconstruction of the microstratigraphy itself. Then, thin and/ or ultra-thin sections (at least two per sample, cut perpendicular to the external surface) were analysed under a polarised light microscope in both transmitted and reflected light.

Given the thinness but above all the composition of the Caoxalate films, essentially made of fine to very fine grained mineral phases, the study of ultra-thin sections is, in our experience, crucial for an appropriate petrographic characterisation of these films. In fact, it permits to recognise the mineral phases present in grains down to a few microns in diameter and, in many cases, to distinguish the microcrystalline aggregates of compounds, in particular the two different Ca-oxalates (whewellite and weddellite) which typically constitute the binder ${ }^{1}$ of these films. The effective thickness of the sections is established by the researcher for each type of film through preliminary attempts to obtain the best visibility of the optical characteristics of the existing mineralogical species and then to recognise these last and their textural relationships.

Observation of ultra-thin sections also permits to survey the aggressive action of 'sulphation' processes, very frequent if not ubiquitous on these films. These processes, induced by sulphate ions carried by water, have two different mechanisms: the first (sulphation in the petrographic sense or 'epigenetic gypsum' as defined in Vergès Belmin et al. 1993) involves a perfect mimetic substitution (volume by volume) of Ca-oxalate crystals by gypsum; the original microcrystalline aggregate structure of the Ca-oxalate is maintained and only its varied birefringence (Gratziu 1986; Baracchini et al. 1991) can indicate, upon microscopic observation, the mineralogical transformation. In the second, more evident and disrupting mechanism, gypsum brought into solution penetrates into the film through microcracks or along the contact with the substratum.

The first mechanism, in particular, if not recognised as such, may erroneously suggest that gypsum is an integral component of the film.

The ultra-thin section technique then permits a very detailed observation of the microstratigraphy, in particular when we are dealing with more than one overlapping film or with further complications induced by sulphation and/or other processes.

\footnotetext{
$\overline{1}$ This term and the complementary one 'filler' are commonly used in petrography to describe the textural relationships, in particular mixtures, between components of different granulometry (e.g. sandstones, mortar, etc.). They are also particularly suitable in Ca-oxalate film descriptions since they normally consist of a homogeneous microcrystalline oxalate phase (binder) in which a quantity of other mineral phases (filler) of variable granulometry is immersed.
}

However, for confirmation and completion of the petrographic characterisation, this technique must be coupled with other analytical methods. In the standard procedure followed in this work, X-ray diffraction (XRD) analyses were carried out using a Philips X'Pert PRO PW 3040 diffractometer (Bragg-Brentano geometry). The analyses were performed on each sample, both directly on its surface and/or on powder gently scraped from it; step-by-step analyses were performed when more accurate stratigraphic information was necessary. Fourier transform infrared was used to confirm the analyses when a very small quantity of sample powder was available. Furthermore, we performed scanning electron microscopyenergy-dispersive spectroscopy (SEM-EDS) analyses on several representative samples of each type of film using a Philips XL20 electron microscope operating at $20 \mathrm{kV}$ acceleration voltage and equipped with an EDAX DX4 energy dispersive spectrometer. EDS data were collected either as raster or spot analyses. Raster analyses were obtained by scanning the beam over small homogeneous areas (ca. $40 \times 20 \mu \mathrm{m}$ ) of the film so as to define a semiquantitative estimate of the major elements present therein. Spot analyses were also performed on single grains or clots of suitable size.

This methodological approach, improved and optimised during the many years of experience on this particular subject, allows a sound petrographic characterisation of the single specimens and thus easy distinction of the different types of films that may be present on a monumental surface.

It must be stressed, however, that the very large number of samples taken was crucial for this kind of research. Such availability, in fact, enabled us to verify other decisive knowledge for the genetic interpretation like the similarity and homogeneity of each type of film over widespread surfaces and its distribution on the different architectonic elements of the facade and/or on the different stone materials.

We precise, finally, that we reserve the term 'Ca-oxalate film' for films in which the binder consists exclusively or at least prevalently of Ca-oxalate, adding 's.s.' (sensu stricto) to those films in which the binder is greatly predominant over the filler. This qualification is necessary to restrict the discussion to the oxalate films involved in the ongoing scientific debate and to avoid possible confusion with various types of finishes on stone surfaces which may contain a minor quantity of oxalate together with the usual binders (lime and gypsum).

\section{Results}

Films on marble

In terms of diffusion, there are two main types of $\mathrm{Ca}$ oxalate films on the marble surfaces of the facade. The first 
type (abbreviated as G1) appears macroscopically in the form of patches, usually of limited extension and with a more or less intense brownish-orange colour (Fig. 3a, b). Traces of G1 were found on both the lower and upper half of the facade and equally on smooth wall and on the various ornamental elements. In thin section, the G1 film consists of a filler of very fine yellow and subordinately orange ochres, rare black carbon and rarer quartz grains in a microcrystalline binder with a whewellite-like aggregate birefringence. It has a mean overall thickness of $20-40 \mu \mathrm{m}$. The filler-binder ratio is heavily in favour of the binder. A layer of microcrystalline calcite, rarely discontinuous and 20-25 $\mu \mathrm{m}$ thick on average, always underlies the G1 film (Fig. 3c, d). Sulphation phenomena are not very frequent in the film but almost ubiquitous in the underlying micritic level. This succession was also observed macroscopically in one of the facade's rare zones of smooth wall, where the G1 film overlies a whitish calcite level that appears slightly coloured due to residues of the upper film (Fig. 3b).

XRD analyses (Fig. 4e) of the G1 film confirm the prevalent presence of an oxalatic phase (whewellite) together with a moderate quantity of quartz and a very small amount of feldspar. Traces of clay minerals are also indicated.

EDS spot analyses performed on rare ochreous clots of suitable size (Figs. 4a, b and 5a, b) reveal that they always contain an abundant (though variable) quantity of elements characteristic of silicates. In the yellow ones, these elements appear normally prevailing over iron (Fig. 4c) whereas the iron content is generally higher in the orange ones (Fig. 5c). The raster analysis (Fig. 4d), representative of the many ones performed on particularly homogeneous areas of the
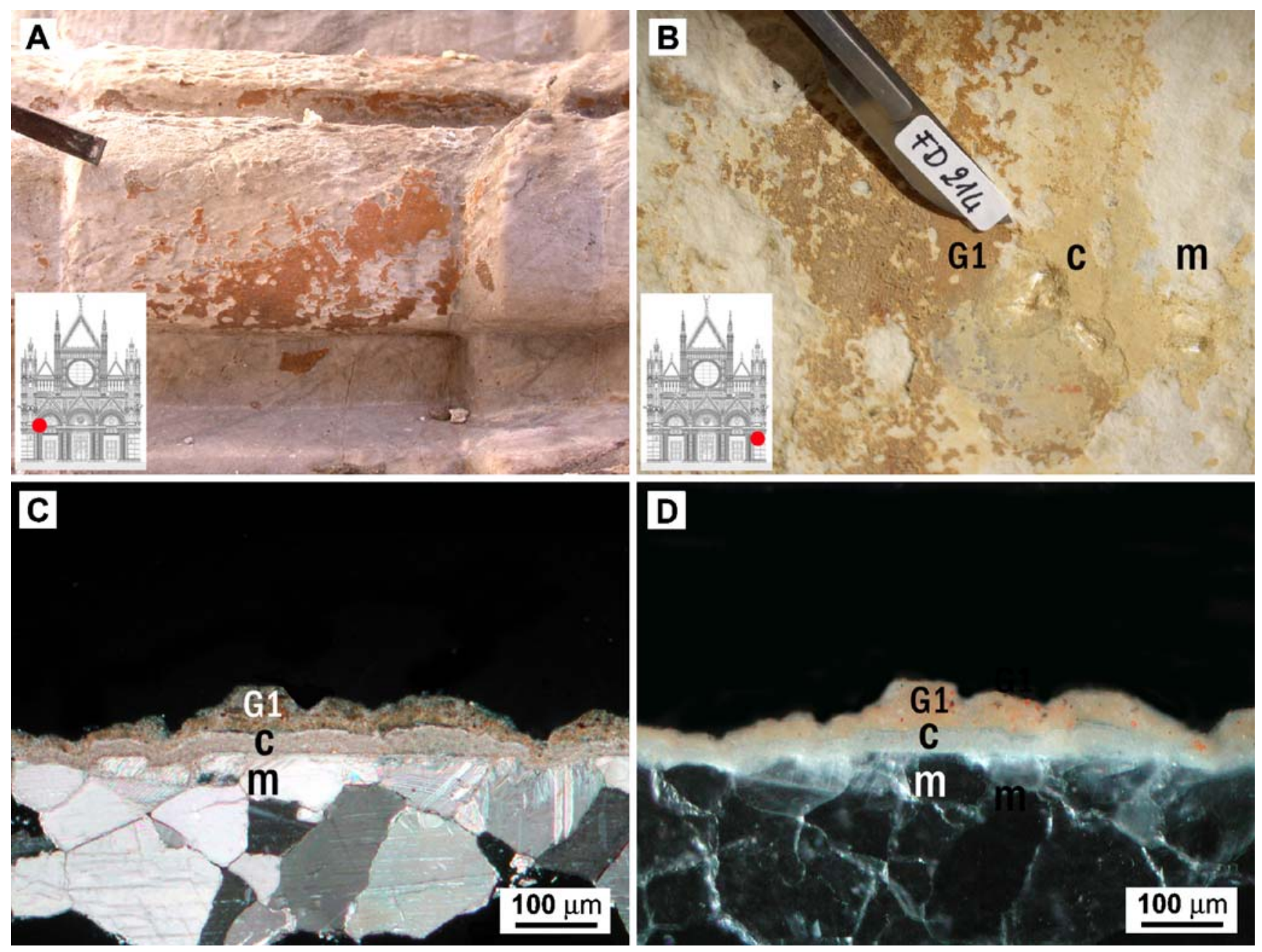

Fig. 3 a Characteristic macroscopic appearance of traces of the G1 type Ca-oxalate film. b In addition to the traces of G1 film, the underlying layer of microcrystalline calcite $(c)$ in contact with the marble $(m)$ is also evident macroscopically. c Microstratigraphy under the polarised light microscope (transmitted light, crossed nicols). Two distinct levels are observed on the marble support $(\mathrm{m})$ : microcrystal-

line calcite $(c)$ overlain by the G1 film. This and all the following transmitted light photographs were taken with the aid of the convergent lens to increase the brightness of the images. d Microstratigraphy (dark-field reflected light). Same view and same symbols as in the previous photograph. Observation in reflected light allows better appreciation of the colour of the G1 film 

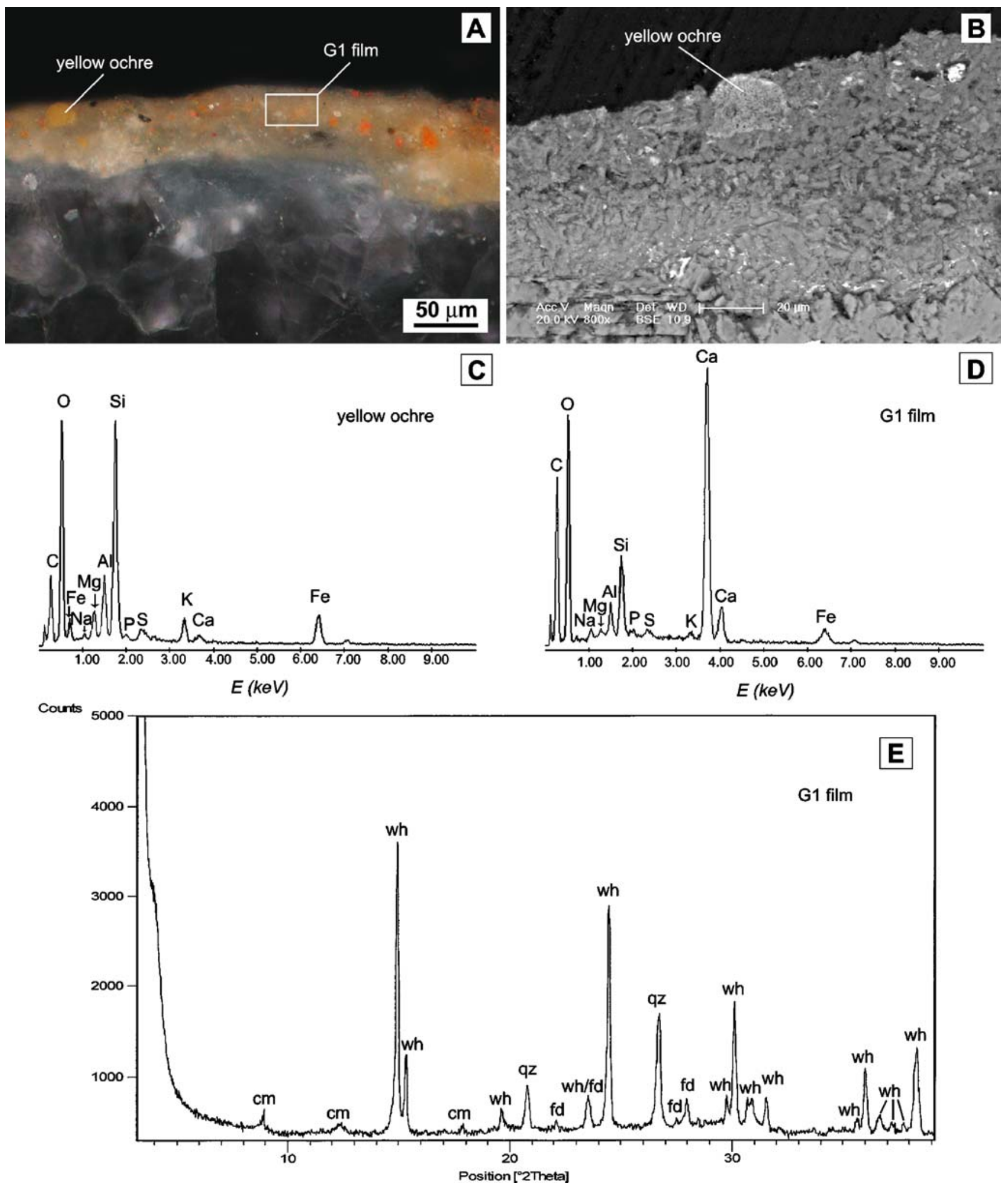

Fig. 4 a G1 film microstratigraphy (dark-field reflected light). The lines point to a large yellow ochre clot and to the small (ca. $40 \times$ $20 \mu \mathrm{m}$ ) analysed homogeneous area of G1. b BSE image, obtained at SEM-EDS, of the yellow ochre clot of a. c EDS spectrum of the yellow ochre clot of $\mathbf{a}$ and $\mathbf{b}$ (spot analysis). d EDS spectrum of the homogeneous area indicated in a (raster analysis). e Representative XRD spectrum of G1 film ( $\mathrm{cm}$ clay minerals, $w h$ whewellite, $q z$ quartz, $f d$ feldspar) 

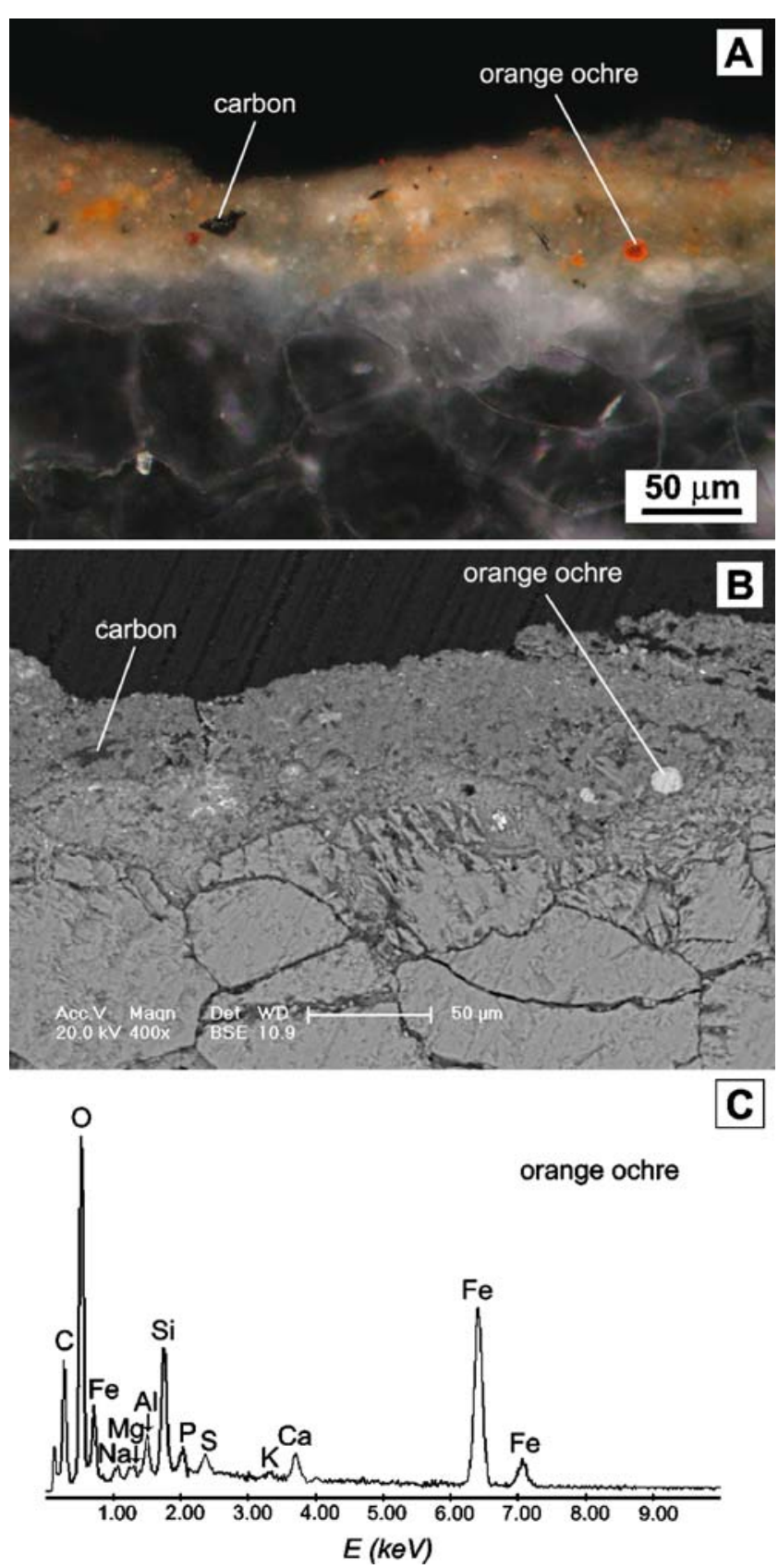

Fig. 5 a G1 film microstratigraphy (dark-field reflected light). The lines point to a carbon fragment and to an orange ochre clot. b The same image of a obtained by SEM with BSE. c EDS spectrum of the orange ochre clot of $\mathbf{a}$ and $\mathbf{b}$ (spot analysis)

film, confirms the XRD data and the microscopic observation, indicating a predominance of calcium and then $\mathrm{Ca}$ oxalate (calcite is absent in G1 according to XRD analyses) over silicates whereas Fe appears as a minor component ${ }^{2}$.

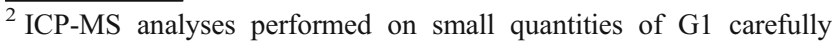
scraped from some large G1 patches indicate an average content of iron around $3 \%$.
}

A semi-quantitative evaluation, combining all the analyses performed on this type of film, indicates that $\mathrm{Ca}-$ oxalate (the binder) represents about $80 \%$ of the whole film whereas the ochreous material (the filler) constitutes the remaining part and, very likely, is the carrier of the silicates.

The second type of oxalate film (G2) was found exclusively in the lower half of the facade, in much larger patches with respect to the G1 film. Macroscopically, its colour varies from yellowish-brown to light brown (Fig. 6a). At the microscopic observation, this film (Fig. 6b) appears much thicker than the G1 film (70$100 \mu \mathrm{m})$ and has a very similar but coarser filler, still consisting of yellow-orange ochres and rare black carbon and quartz grains, in a very prevalent $\mathrm{Ca}$-oxalate binder (whewellite). It is often interrupted by fissures perpendicular to the surface and very similar to a craquelure, which are easily observed macroscopically too. Signs of sulphation are frequent and pervasive in the G2 film and appear to be correlated to the light brown colour it often assumes. XRD and EDS analyses confirm the mineralogical and chemical similarity between G1 and G2. For both types of film, there is strong homogeneity of the filler-binder mixture in all the samples.

In several cases, the thin sections show superimposition of the G2 film on the G1. In Fig. 6d, the two films are separated by an encrusting calcite layer with palisade structure. The overlapping of the two films can even be observed macroscopically in an area of the right portal (Fig. 6c).

In some samples, the G2 film is also superimposed on another type of Ca-oxalate film (GE). The GE film has a much smaller diffusion than the other two types, being restricted to a well-defined sector of the facade, i.e. the cuspidate areas above the portals. Macroscopically, it appears as small brownish-yellow patches (Fig. 7a). In thin section, GE is very similar to G1, with a slightly coarser filler; the very prevalent binder is once again whewellite. XRD and EDS analyses indicate a compositional similarity with G1 in this case as well. What clearly distinguishes GE from $\mathrm{G} 1$ is that it rests on a layer consisting of microcrystalline calcite plus fine powdered marble, which is a very thin plaster instead of only micrite (Fig. 7b).

For completeness, we should mention that we also identified two other types of Ca-oxalate films similar to the preceding ones but with different petrographic characteristics. They appear to be located in well-defined and very limited sectors of the facade. For brevity, we will not describe them in detail here.

According to the criteria established in the 'Methodology' section, all the abovementioned films must be considered Ca-oxalate films s.s.

Finally, we must mention a last type of film (P), distinct from the preceding group in that it is not a $\mathrm{Ca}$-oxalate film. Macroscopically, it is observed almost everywhere on the facade, usually in the form of small mainly whitish relicts, 

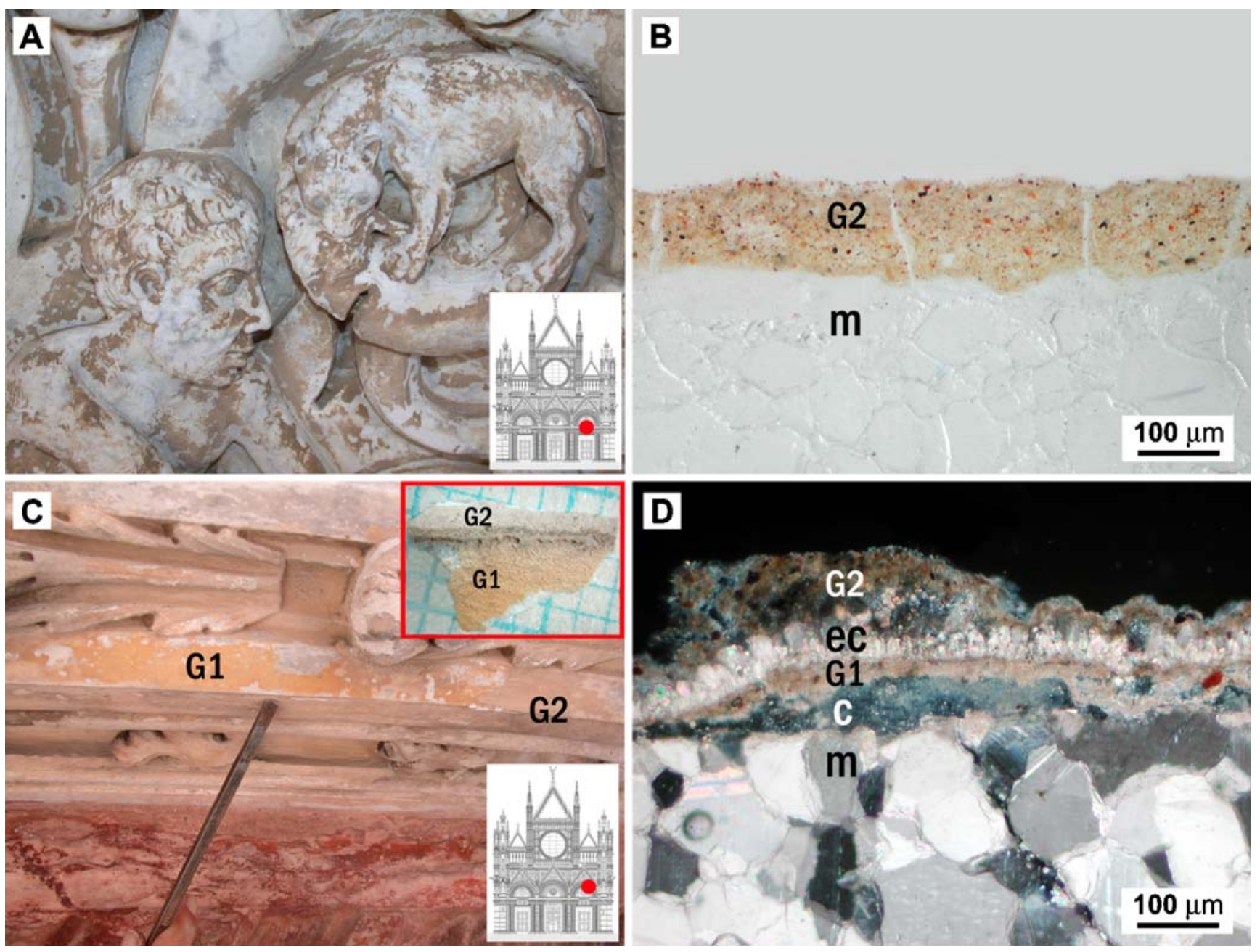

Fig. 6 a Characteristic macroscopic appearance of traces of the G2 type Ca-oxalate film. b Microstratigraphy (dark-field reflected light, with a white paper under the thin section). Marble (m); G2 film. The fissures perpendicular to the surface (craquelure) are visible in the film. c Zone of the right portal. Trace of the G1 film overlain by a G2 film (the photograph in the insert was taken with a stereomicroscope).

although varying from greyish to light yellow in places. It is found directly on the marble and also overlying the G1, G2 and GE films (Fig. 8a). In thin section, it consists mainly of microcrystalline calcite (sometimes microsparite) with very rare coarse granules of yellow-orange ochres and black carbon (Fig. 8b). The presence of oxalate was never recorded (nor in the XRD analyses). The thickness is fairly constant, around $60 \mu \mathrm{m}$ on average. This film is often very porous, which, combined with its composition, has facilitated the intense phenomena of pervasive sulphation observed in almost all the samples.

Films on red ammonitic limestone

Relicts of Ca-oxalate films are much rarer on this material than on marble, which can be explained by the strong decay d Microstratigraphy (transmitted light, crossed nicols). The thin section of a sample taken in the zone of confirms the overlapping of the two films (G1 and G2) separated by a level of encrusting calcite $(e c)$. In this case, the microcrystalline calcite $(c)$ underneath the G1 film is almost totally sulphated

and extensive recent substitutions of this stone. Actually, the zone of the right portal is the only one with frequent traces of these films, also because it was not subjected to excessive cleaning in recent restorations. The spiral mouldings of the arch of this portal are particularly interesting since they are considered original, and thus we concentrated our study on them. Traces of colouring treatments on these mouldings, in the form of dark red patches with orange striations, are sometimes evident at the macroscopic level (Fig. 9a, b).

At the microscopic observation, the samples show, from the bottom upwards, a succession of three distinct film types. The first (R1) is generally thin (mean thickness around $20 \mu \mathrm{m}$ ) and consists of a whewellite binder with a scarce fine yellow-orange ochre filler (Fig. 9c, d). The observation of numerous sections indicates that R1 is often discontinuous 

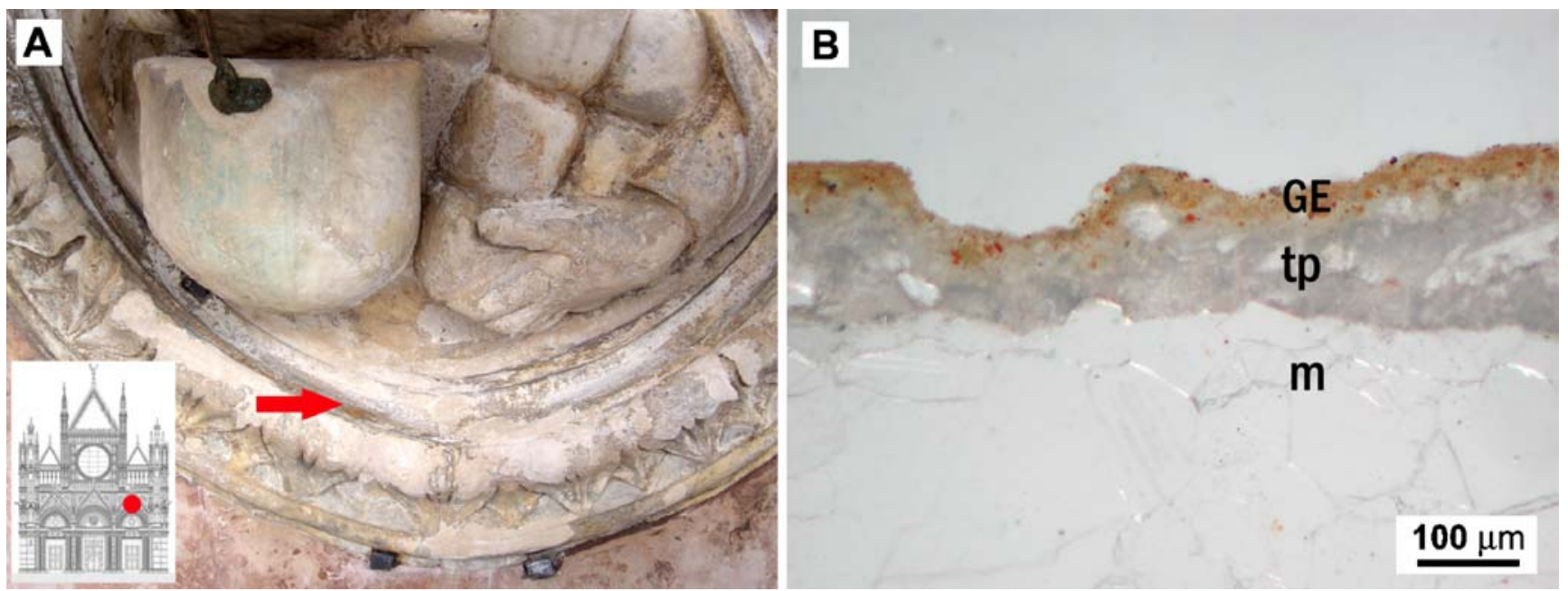

Fig. 7 a Right portal. Small trace of the GE film on the cornice surrounding the Sienese saint. b Microstratigraphy (dark-field reflected light, with a white paper under the thin section). Two distinct levels are observed on the marble support $(m)$ : a very thin plaster $(t p)$ overlain by the GE film

(or even absent) and sometimes partially detached from the substratum. The second (R2) is composed of a dense filler of very coarse red ochres and rare black carbon in a binder consisting of microcrystalline calcite (mean thickness around $50 \mu \mathrm{m})$. In many samples, the calcite of the binder has almost disappeared, sometimes replaced by gypsum or even leaving voids (Fig. 9c, d). Diffractometric analyses showed the additional presence, albeit in a smaller quantity, of Ca-oxalate dihydrate (weddellite). The third film (R3) is much more homogeneous, with an abundant filler of fine orange ochres in a whewellite binder. This mixture often penetrates into the voids in the R2 film (Fig. 9d). Figure 9e shows a residue of R2 separated from R3 by a layer of plaster. XRD and EDS analyses indicate for R1 the presence of a smaller quantity of silicates in comparison

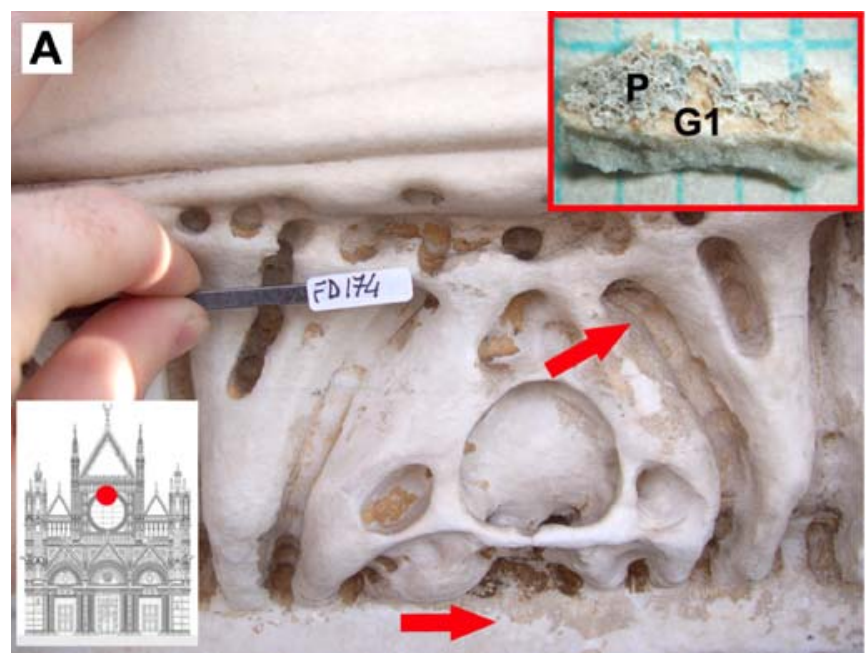

Fig. 8 a Rose window. Traces of the P film on the cornice. In this case, the P film overlies the G1 film (the photograph in the insert was taken with a stereomicroscope). b Microstratigraphy (transmitted to $\mathrm{G} 1$ but a similar $\mathrm{Si} / \mathrm{Fe}$ ratio. For R3, the silicate content is similar, but the $\mathrm{Si} / \mathrm{Fe}$ ratio is much lower.

As per the previous definition, R1 and R3 are classified as Ca-oxalate films s.s., whereas $\mathrm{R} 2$ cannot be considered a $\mathrm{Ca}$-oxalate film since it has a predominantly calcite binder.

\section{Films on serpentinite}

Relicts of Ca-oxalate films on serpentinite are also rare and concentrated in small sectors, for the same reasons reported for red ammonitic limestone. Macroscopic identification of traces of Ca-oxalate films on serpentinite elements is not easy because the decay that usually affects such films often renders them anonymous dirty white or pale yellow patches indistinguishable from other surface stains present for various reasons

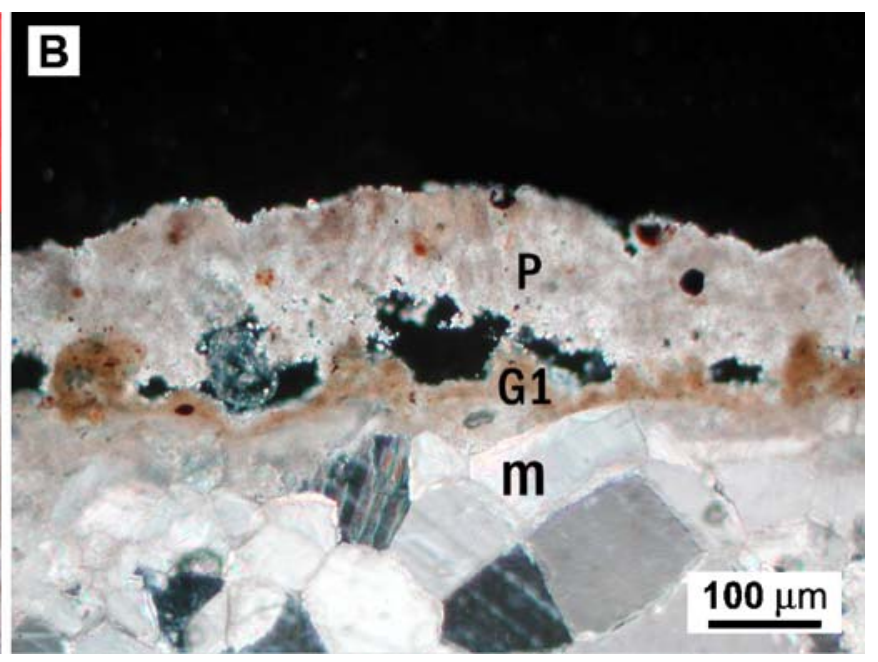

light, crossed nicols). The thin section of a sample taken in the zone of a confirms the overlapping of the two films (P and G1) on marble $(m)$ 

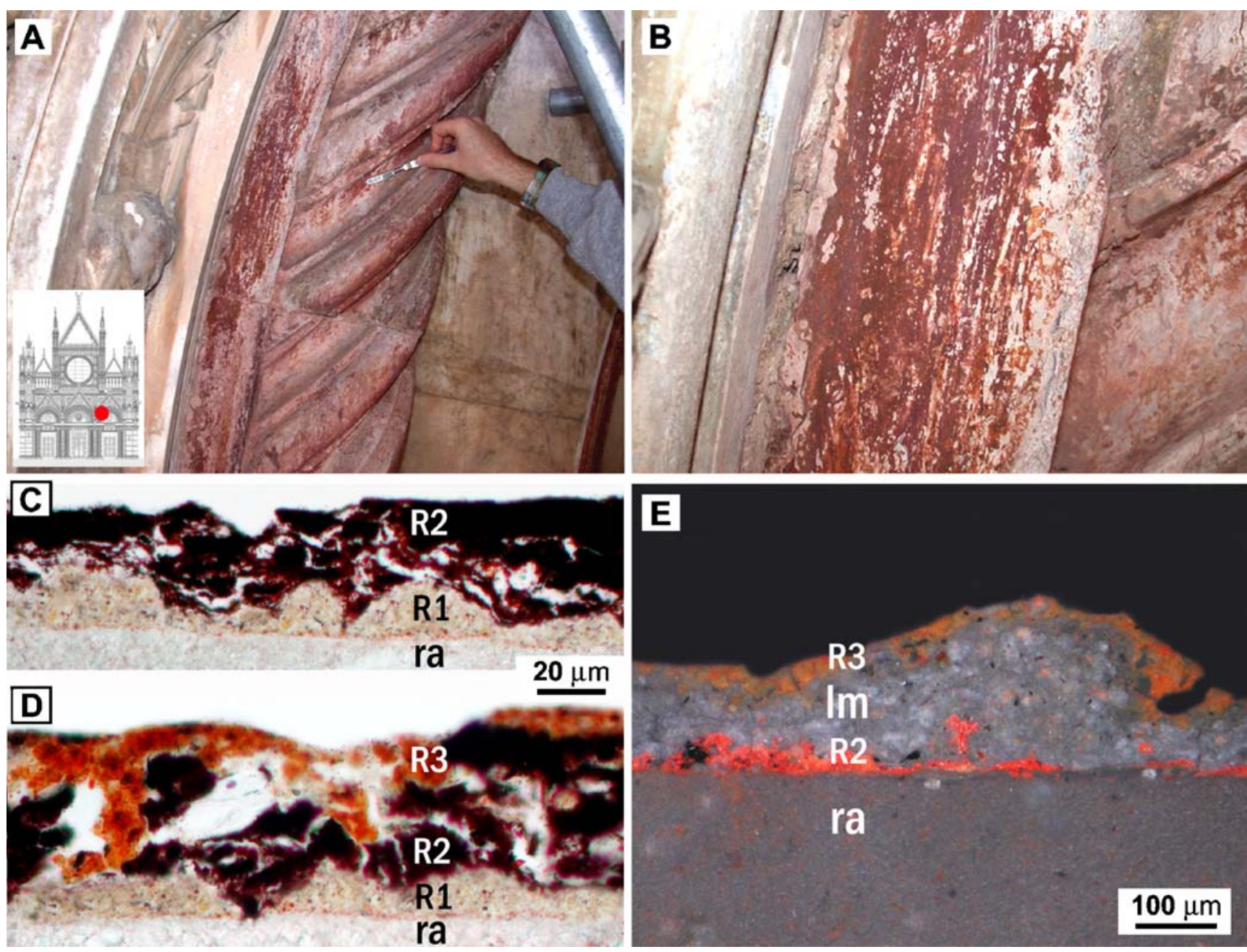

Fig. 9 a Right portal. Characteristic appearance of traces of colouring treatments on red ammonitic limestone of one of the spiral mouldings of the arch. b Detail of the preceding figure. The colouring treatment appears as dark red patches with orange striations. $\mathbf{c}$ Microstratigraphy (transmitted light, one nicol). The thin section of a microfragment taken from a zone of darker red colour than in b shows the following succession of layers: red ammonitic limestone support $(r a)$; R1 film, with scarce ochre filler in a Ca-oxalate binder; R2 film with a coarse red ochre filler. Large voids are observable in this layer. d Microstratigraphy

or from other phenomena caused by degradation of this stone material. This difficulty was also encountered in previous studies of historical Sienese buildings: Town Hall (Giamello et al. 2005), Rettore Palace (Nardelli 2005) and the lateral portal of the Duomo Nuovo (Ceccherini 1989).

Figure 10a shows the macroscopic appearance of these films in a rare case where there are small islands characterised by a greenish colour with borders highlighted by yellowish-white halos. In thin section (Fig. 10b), they consist of Ca-oxalate (whewellite) alone, sometimes with small quantities of very fine black carbon. A careful study of many thin sections revealed that the greenish islands correspond to zones devoid of sulphation phenomena, so that the film is transparent and the typical colour of the (transmitted light, one nicol). The thin section of a microfragment taken from a red striation of more orange colour than in $\mathbf{b}$ shows the same microstratigraphy of the preceding figure except the presence of a third film (R3) consisting of yellow-orange ochres, in a Ca-oxalate binder, penetrating into the voids in the underlying film (R2). e Microstratigraphy (dark-field reflected light). The photograph shows the R2 and R3 films separated by a coat of lime mortar ( $(\mathrm{m})$. In this optical condition, the films' colours are more real

stone is visible. In the halos, in contrast, sulphation is ubiquitous and intense. This causes disconnection of optical contact between the film and the substratum and the film becomes an opaque coating (see also Droghini et al. 2009).

This type of film, usually rather thin (about 10-20 $\mu \mathrm{m}$ ) and with characteristics very similar to those of films observed on this stone material in previous studies, is the only one present on serpentinite. XRD analyses show that whewellite is the only mineralogical phase present. EDS analyses do not reveal the appreciable presence of any other component.

As a final comment of the preceding analytical and descriptive data, it is worth to remark that many of the film 


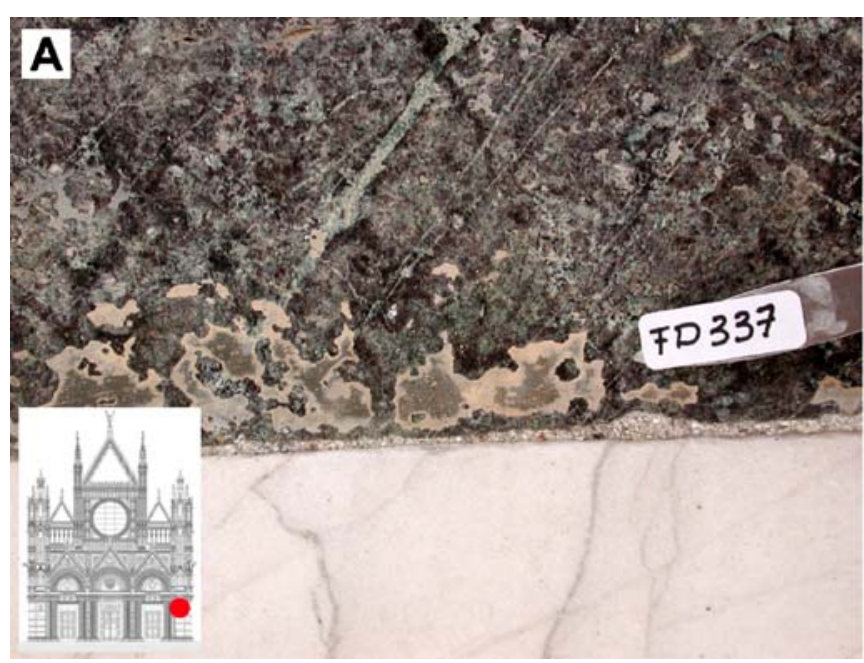

Fig. 10 a Relict of Ca-oxalate film on serpentinite characterised by small greenish islands and yellowish-white halos. b Microstratigraphy (transmitted light, crossed nicols). The photograph shows the Ca-

types above distinguished (G1, G2, GE, R1 and R3) are to be considered, on the basis of XRD and EDS analyses alone, very similar.

On the contrary, their appearance at the microscope in ultra-thin section is distinctly diverse. Small difference in the proportion of the same components (Ca-oxalate and ochreous earths), small difference in the yellow and orange ochres mixtures, or even only a different granulometry of the filler is sufficient to make a great difference in their look at the microscope.

\section{Discussion}

Origin and meaning of the films

The results of our study confirm the findings of previous investigations and provide further information bearing on the aims of the research outlined in the 'Introduction'. The three lithotypes that constitute the facade present different types of Ca-oxalate films, each of which is never found on the other types of stone. In other words, each film is characteristic of and exclusive to a single stone material. Moreover, all the types of films have a constant thickness and a constant homogeneity of the internal distribution of filler and oxalate phase. It is important to repeat that the constituents of the filler are never random; on the contrary, for each type of film, they are always the same and exclusively represented by $\mathrm{Fe}$ ochres or black carbon or a combination of the two. All these characteristics, exactly mirroring the findings of our previous studies on other Sienese monuments, confirm the anthropic origin of these films. No natural process, be it the action of organisms or atmospheric deposition, can adequately explain these

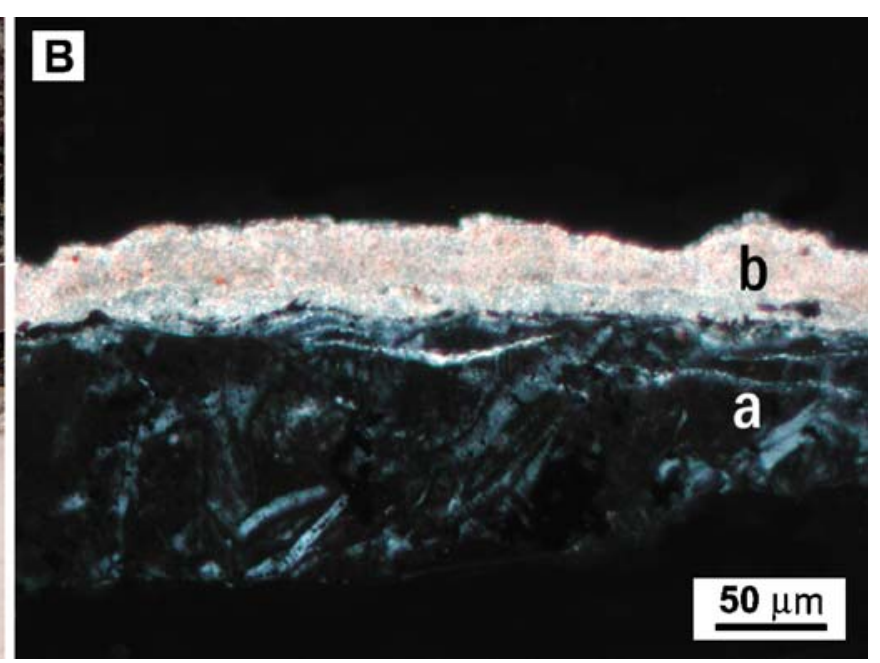

oxalate film $(b)$ on serpentinite $(a)$. Sulphation of the film, visible in its lower part with minor birefringence, causes the optical disconnection with the substratum (see text)

characteristics, nor can other evidence that will emerge later.

If then they are anthropic, it is also true that the current appearance of the films cannot correspond to their primitive appearance, at least because the oxalate phase cannot be original. Unfortunately, too little is known about the exact process (physico-chemical?, bacterial?) by which many organic substances can give rise to oxalates; nevertheless, many authors agree that this transformation is possible, and for some of them (e.g. egg yolk, casein, linseed oil, etc.), this trend has been experimentally proven (Franzini et al. 1984; Camaiti et al. 1996). All these facts indicate that these films were originally mixtures of an organic substance that acted as binder plus a filler still recognisable as a pigment component. The transformation of the binder and, above all, the sulphation processes which, with the advent of the industrial era, have pervasively and severely attacked the films (ultimately leading to their detachment from the substratum) have profoundly changed their original appearance and made their recognition much more difficult (Droghini et al. 2009). This explains the long scientific debate mentioned previously.

However, the role of these films must also be clarified. Experimental trials (under way, in collaboration with the Opificio delle Pietre Dure) with mixtures of linseed oil and a filler, that is qualitatively and quantitatively identical to the one present in films on the marble of Jacopo della Quercia's Fonte Gaia, have revealed what must have been the original appearance of these treatments (Fig. 11): a soft ivory-coloured glazing (in the pictorial meaning of the term) that allows the marble to be seen but at the same time gives it a brighter tonality and renders the colour more homogeneous by attenuating irregularities due to the greyish or yellowish veins so frequent in this material, 


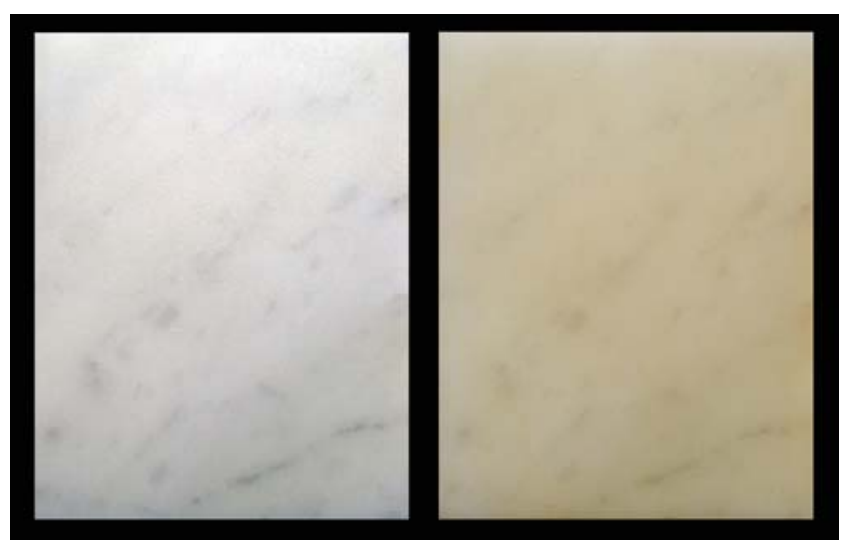

Fig. 11 The same small marble slab as it appears before (left) and after (right) the treatment (see text)

especially the Montagnola Senese marbles. The function of the G1, G2 and GE films must have been similar; despite the small differences in petrographic features, their fillers are similar to each other and to those of the film on the Fonte Gaia. In particular, all these films are of the s.s. type, with a filler that has a much smaller volume than the (now oxalate) binder. In reality, there is a significant difference for G1 and GE, in that they do not rest directly on the marble but overlie a thin homogeneous and continuous layer of microcrystalline calcite or thin plaster, respectively. In all probability, this layer corresponds to a coat of lime (with or without powdered marble), likely applied to the surface to obliterate or mitigate the colour irregularities of the underlying marble and thus render the tonality of the subsequent finish even more homogeneous.

Lastly, the P film was found on both the lower and upper halves of the facade and presumably involved most, if not all, of the marble surfaces. As specified previously, it is not a Ca-oxalate film and it has the characteristics of a normal lime finish aimed at restoring a uniform white tonality (attenuated by the scarce pigments of the filler) to the surfaces.

Previously, we mentioned the presence on marble of other films with different petrographic features, albeit still attributable to glazings like G1 and G2. Since their distribution is limited to very small areas of the facade, we believe that they represent treatments of small zones necessary to adapt the surfaces to the colour of the surrounding areas after substitutions or other local interventions.

The R1 and R3 films on red ammonitic limestone also have the characteristics of glazings. Hence, their function was to render homogeneous, highlight and maintain the natural colour of the stone which, as can be observed on the untreated surfaces, is very inhomogeneous and also tends to fade and almost disappear with direct exposure to atmo- spheric agents. The R2 film instead can be interpreted as a non-transparent finish, whose lime-red ochre mixture reproduced the average colour of the stone, making the surfaces of this material completely uniform.

The film observed on serpentinite again represents a glazing. No other role can be envisaged for this treatment since the film now consists mainly of Ca-oxalate (and thus originally only linseed oil) sometimes with small quantities of fine black carbon. Again, the aim was to highlight and maintain the natural colour of the stone via the lasting 'wet effect' of the linseed oil. The colour was rendered more homogeneous by the presence of black carbon, able to attenuate the frequent chromatic variations present in this material. In this case, we have confidently indicated the nature of the original organic substance. In fact, the recent paper by Giorgi and Moscadelli, based on a rigorous and detailed examination of the archive relative to the fourteenth century construction work on the Cathedral, cites several invoices which, thanks to their purchase description, leave no doubt on this matter (Giorgi and Moscadelli 2005, note 122 p. 215):

oglio di semelino che si comprò per tignare marmi neri" ( 2 soldi e 6 denari)

"nero ad olio per ognale marmi neri" (18 soldi)

(linseed oil bought to stain black marbles)

(black with oil to anoint black marbles)

These historical documents from the 1300s not only attest to the normal practice, at that time, of treating stone materials but even specify the organic substance from which, at least in our case, the oxalate phase originated.

\section{Chronology of the treatments}

Before concluding, it remains to deal with another important topic, i.e. an attempt to reconstruct the chronological context of the films recorded on the facade. The historical reference cited previously testifies to the use of these techniques already in the fourteenth century, and, as we will see, they were undoubtedly used in the following centuries. Therefore, we must first determine which of the identified films can be considered original and then try to date the other films.

For marble, there are good reasons to consider the G1 film an original treatment. In all cases, in fact, it is always in direct contact with the marble via the preparatory lime coat; more importantly, the traces of this film are, without exception, only found in the sectors of the facade that Haas and von Winterfeld considered the only original ones (Fig. 2). Moreover, this film is also present, and always directly in contact with the substratum, on indisputably original elements of the facade such as the architrave of Tino di Camaino (in its left portion, the only well preserved 
one) and on the columns of Giovanni Pisano, currently housed in the Museum of the OPA.

The GE film was only found on the cuspidate areas above the portals, more precisely on the architectural elements indicated by historical research (Forlani Conti 1992) as dating to the seventeenth century (1636-1659). In addition, it appears to be identical, including the preparatory coat of thin plaster, to the film on the surface of the south-east wall (built in the same period), which is currently under study. Therefore, it is very likely that this treatment was carried out in that historical period to adapt the colour of the replacement elements to that of the surrounding parts.

The G2 film is superimposed on both the G1 and GE films. It was only found in the lower half of the facade where it appears very diffuse, especially in the area of the portals on elements dating to the eighteenth century (Butzek 2006). Indeed, many substitutions in the lower part of the facade were documented in the early 1700 s, and evident traces of G2 are present on these parts and on a slab bearing the sculpted date ' 1704 '. This is the most probable age of G2 although we cannot exclude a later date, perhaps immediately after the work carried out following the 1798 earthquake.

Finally, the P film is superimposed on G2 in several samples and, more importantly, directly overlies the marble in replacement elements set in place in the second half of the 1800s by Partini (Forlani Conti 1992). Therefore, we consider this its most probable age.

Information to date the films on red ammonitic limestone is relatively scarce and only allows some hypotheses. Traces of three superimposed films were found on this lithotype. They refer to a very restricted sector of the facade, albeit a very important one since it is one of the very few original representatives of red ammonitic limestone. The only film to which we can give a certain date post-quam is R3, which was found, in direct contact with the substratum, on one of the spiral columns of the right portal replaced in the early 1700s (Butzek 2006). The R1 film, in direct contact with the red ammonitic limestone of one of the few original elements in the facade, could be the equivalent of the G1 film on marble. This is suggested by the similarity of R1 to an analogous film found on the red ammonitic limestone of the Piazza del Campo Chapel built by the same craftsmen of the Opera del Duomo between 1366 and 1380. Indeed, a precise reference to an original treatment of the red ammonitic limestone of the Piazza del Campo Chapel (further evidence of the habitual use of linseed oil and coloured earths in this kind of treatment) is found in Giorgi and Moscadelli (2005, note 434 p. 269):

per una libbra d'oglio di semelino che s'adoparò al marmo rosso et nero della mora

et per due libbre di sinopia et per due libbre di nero" (for a pound of linseed oil used for the red and black marble of the pilaster

and for two pounds of sinopite and for two pounds of black)

The application of R2 can be attributed to the seventeenth century interventions or, at the latest, to the work in the early 1700 s.

Also for serpentinite, traces of film were only detected in a limited sector of the facade but again in a zone believed to be original. In this case, the previously mentioned historical evidence of a fourteenth century treatment of this stone material makes any further comment unnecessary.

\section{Conclusions}

The results of this study fully confirm an ancient custom of applying finishes to all the stone materials used in entire facades. The aesthetic role of the finishes is evident although they also had a concomitant protective action (intended or not) on materials of often mediocre durability. The types of treatments indicate an aesthetic taste aimed at enhancing the natural colour of the stone, by rendering it more homogeneous, highlighting it and preserving it in time, as well as creating a better chromatic harmonisation of the entire facade. The last purpose was perhaps why an ivory tonality was preferred for the marble, or to give this material a more valuable appearance.

Our results confirm that these finishing techniques were habitually used at least as far back as the 1300s and that they continued to be applied for a long period of time. The results of an ongoing study of the Cathedral's south-east wall (built in 1636-1659) and north-west wall (1730-1732) are also interesting in this regard. As hinted above, traces of a film referable to a glazing identical to GE were found on the marble of the south-east wall, while the serpentinite of both walls contains traces of films very similar to those on the main facade. Hence, we can infer that the use of these treatments persisted through the centuries.

Moreover, the results of studies on other historical Sienese buildings (already cited in the 'Introduction') also attest to the generalised use of these treatments. Traces of finishes similar to the ones described in the present paper were found on all the typical Sienese stone materials (including pietra da torre), even if used for single ornamental elements of the facades.

Acknowledgements The authors wish to thank the Opera della Metropolitana of Siena, and especially its Rector Dr. M. Lorenzoni, for permitting sampling of the Cathedral's facade. They are also indebted to Dr. M. Butzek and Dr. W. Loseries of the Kunsthistorischen Institut in Florence for the valuable historical information provided during this study. Special thanks go to Professors A. Giorgi 
and S. Moscadelli for having brought to our attention historical documents of inestimable importance for this work.

\section{References}

Alessandrini G (1989) Proceedings of the International Symposium "The oxalate films: origin and significance in the conservation of works of art". Centro CNR "Gino Bozza", Milano, Italy

Álvarez De Buergo Ballester M (2007) Pátinas en el Patrimonio Histórico. Macla 7:13-14

Baracchini C, Caponi G, Gratziu C, Manganelli Del Fa' C, Spampinato M (1991) Finitura delle superfici lapidee e decorazione policroma nel S. Michele in Foro a Lucca: dati preliminari. In: Proceeding of the Congress "Le pietre nell'architettura: Struttura e Superfici”. Bressanone, Italy, 25-28 June 1991, pp 621-631

Butzek M (1996) Il Duomo di Siena al tempo di Alessandro VII: Carteggio e disegni (1658-1667). In: Die Kirchen von Siena, Peter Anselm Riedl und Max Seidel, Beiheft 2, München, Germany

Butzek M (2006) Der Dom S. Maria Assunta: Architektur. In: Die Kirchen von Siena, hg. v. Peter Anselm Riedl and Max Seidel, vol. 3.1.1.1, München, Germany

Camaiti M, Fommei C, Giamello M, Sabatini G, Scala A (1996) Trattamenti di superfici lapidee secondo antiche ricette: primi risultati sulla formazione di ossalati di calcio. In: Realini M, Toniolo L (eds) Proceedings of the international symposium on the oxalate films in the conservation of works of art. Editeam, Bologna, pp 287-298

Carli E (1979) Il Duomo di Siena. SAGEP, Genova

Ceccherini S (1989) L'alterazione dei materiali lapidei costituenti il portale laterale del Duomo Nuovo di Siena. Geological Sciences Master Degree Thesis, University of Siena, Italy

Droghini F, Giamello M, Guasparri G, Mugnaini S, Sabatini G, Scala A (2007) Le antiche finiture dei "marmi" della facciata del Duomo di Siena. In: Lorenzoni M (ed) La facciata del Duomo di Siena. Iconografia, stile, indagini storiche e scientifiche. Silvana, Milan, pp 175-187

Droghini F, Gabbrielli F, Giamello M, Guasparri G, Mugnaini S, Sabatini G, Scala A (2009) The colour of the façades in Siena's historical centre. (II) - Calcium oxalate films on brickwork of XV-XVI century palaces. In: Science and Technology for Cultural Heritage (in press)

Fommei C, Giamello M, Sabatini G (1993) Il "rosso ammonitico" nella facciata del Battistero di Siena. Osservazioni preliminari sul degrado e sulle formazioni superficiali. In: Forlani Conti M (ed) Il Duomo di Siena. Documenti-Studi-Restauri. Siena, Italy, pp 21-32

Forlani Conti M (1992) Environmental and Architectural Heritage Superintendence of Siena Document. Prot. № 10515 Pos. H-43, September 19, Siena, Italy

Forlani Conti M (1993) Il Duomo di Siena. Documenti-StudiRestauri, Siena, Italy

Franzini M, Gratziu C, Wicks E (1984) Patine ad ossalato di calcio su monumenti marmorei. Rendiconti della Società Italiana di Mineralogia e Petrologia 39(1):59-70

Garcia-Valles M, Vendrell-Saz M, Molera J, Blasquez F (1998) Interaction rock-atmosphere: patinas on Mediterranean monuments. Environ Geol 36(1-2):137-149

Giamello M, Guasparri G, Mugnaini S, Sabatini G, Scala A (2005) I colori della facciata del Palazzo Pubblico di Siena nell'età medievale. Un tentativo di ricostruzione tramite le pellicole ad ossalati di calcio. In: Tolaini F (ed) Proceedings of the Congress "Il colore delle facciate: Siena e 1'Europa nel Medioevo", Siena, 2-3 March 2001. Quaderni CERR, Pacini, Pisa, pp 35-51

Giorgi A, Moscadelli S (2005) Costruire una cattedrale. L'Opera di Santa Maria di Siena tra XII e XIV secolo. In: Die Kirchen von Siena, hg. v. Peter Anselm Riedl und Max Seidel, Beiheft 3, Deutscher Kunstverlag, München, Germany

Gratziu C (1986) Primi dati sulle caratteristiche petrografiche e stratigrafiche delle patine ad ossalato di calcio sui monumenti marmorei romani. In: Proceedings of the Congress "Manutenzione e Conservazione del Costruito tra Tradizione e Innovazione", Bressanone, Italy, 24-27 June 1986, pp 751-763

Haas W, Winterfeld D v (1999) Der Dom S. Maria Assunta. Architektur. Planband. In: Die Kirchen von Siena, hg. v. Peter Anselm Riedl und Max Seidel, Band 3.1.3, München, Germany

Haas W, Winterfeld D v (2006) Der Dom S. Maria Assunta. Architektur. Textband. In: Die Kirchen von Siena, hg. v. Peter Anselm Riedl und Max Seidel, Band 3.1.1., München, Germany

Loseries W (2006) Restaurierungen und Denkmalpflege des Doms 1798-1998. In: Der Dom S. Maria Assunta: Architektur (Die Kirchen von Siena, hg. v. Peter Anselm Riedl and Max Seidel, vol. 3.1.1.2), München, Germany, pp 621-670

Maravelaki-Kalaitzaki P (2005) Black crusts and patinas on Pentelic marble from the Parthenon and Erechtheum (Acropolis, Athens): characterization and origin. Analytica Chimica Acta 532:187198

Martin-Gil J, Ramos-Sanchez MC, Martin-Gil FJ (1999) Ancient pastes for stone protection against environmental agents. Stud Conserv 44:58-62

Nardelli MG (2005) I materiali lapidei della facciata del Santa Maria della Scala (Siena): stato di conservazione, diagnosi del degrado e studio delle tracce di trattamenti antichi. Ph.D. thesis on the Science and Technology of Industrial Minerals and Stones, XVII ${ }^{\circ}$ cycle, University of Sassari, Italy

Peduzzo E (1993) Copie e originali nella facciata del Duomo di Siena. In: Forlani Conti M (ed) Il Duomo di Siena. Documenti-StudiRestauri. Siena, Italy, pp 83-199

Polikreti K, Maniatis Y (2003) Micromorphology, composition and origin of the orange patina on the marble surfaces of Propylaea (Acropolis, Athens). Sci Total Environ 308:111-119

Quast M (2007) La facciata occidentale del Duomo Vecchio: l'architettura. In: Lorenzoni M (ed) La facciata del Duomo di Siena. Iconografia, stile, indagini storiche e scientifiche. Silvana, Cinisello Balsamo, Milan, pp 97-129

Rampazzi L, Andreotti A, Bonaduce I, Colombini MP, Colombo C, Toniolo L (2004) Analytical investigation of calcium oxalate films on marble monuments. Talanta 63:967-977

Realini M, Toniolo L (1996) Proceedings of the international symposium on the oxalate films in the conservation of works of art. Editeam, Bologna

Vazquez-Calvo C, Alvarez De Buergo M, Fort R (2007) Overview of recent knowledge of patinas on stone monuments: the Spanish experience. In: Prikryl R and Smith BJ (eds) Building stone decay: from diagnosis to conservation. Geological Society, London, Special Publications, 271, pp 295-307

Vendrell-Saz M, Krumbein WE, Urzì C, Garcia-Vallès M (1996) Are patinas of Mediterranean monuments really related to the rock substrate? In: Riederer J (ed) 8th International Congress on Deterioration and Conservation of Stone, 2, pp 609-62

Vergès Belmin V, Pichot C, Orial G (1993) Elimination de croûtes noires sur marbre et craie: à quel niveau arrêter le nettoyage? In: Congress on the conservation of stone and other materials, Paris, 29 June-1 July 1993, vol. 2, RILEM/UNESC 